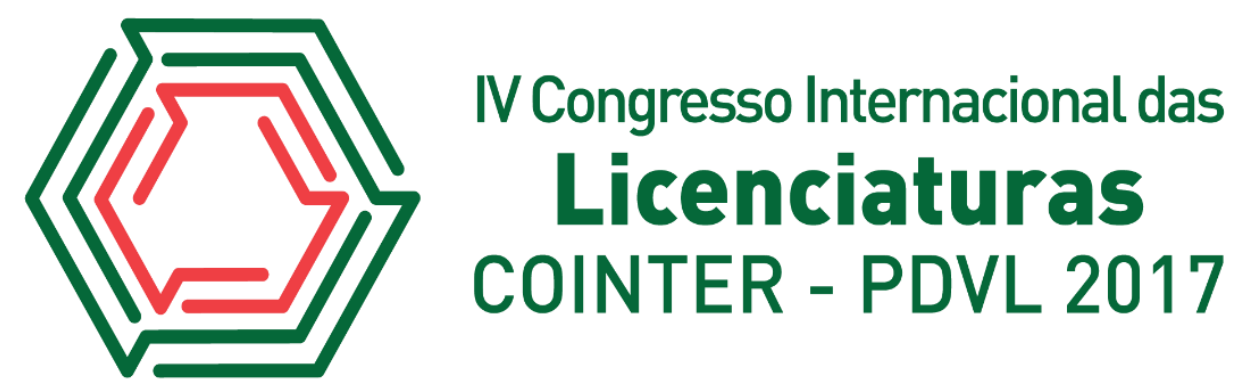

\title{
O USO DE FERRAMENTAS TECNOLÓGICAS DE ENSINO A SERVIÇO DA INCLUSÃO DE ALUNOS COM DEFICIÊNCIA INTELECTUAL NA ESCOLA PÚBLICA
}

\author{
Apresentação: Comunicação Oral \\ Kamene Costa de Sousa ${ }^{1}$; Wanderson Lopes dos Santos Freitas ${ }^{2}$; Mauricio dos Santos \\ Araújo $^{3}$; Arlete Fragas da Silva Rocha ${ }^{4}$ Sebastiana Ceci Sousa ${ }^{5}$;
}

\begin{abstract}
Resumo A deficiência intelectual é caracterizada pela redução do quociente cognitivo, normalmente abaixo do esperado para a idade da criança ou do adulto, acarretando muitas vezes uma lentidão no desenvolvimento neuropsicomotor, dificuldades de compreender ideias abstratas, obedecer a regras, situar-se em relações de autocuidado, entre outras habilidades. A presente pesquisa buscou conhecer as dificuldades encontradas no processo ensino aprendizagem na inclusão de alunos com deficiência intelectual em sala de aula, estas, mencionadas pela gestão escolar, e a partir daí, apresentar recursos tecnológicos que auxiliem na qualidade da aprendizagem dos alunos com essa deficiência. A realidade em questão é uma escola pública municipal de Floriano/PI. Pesquisa de cunho qualitativo, com enfoque descritivo, proporcionando assim uma maior interpretação sobre os resultados obtidos. O instrumento de coleta de dados foi uma entrevista por pautas, realizada com o gestor escolar da Escola Municipal José Francisco Dutra, a fim de conhecer o público alvo de alunos com necessidades especiais que frequentam a escola. Posteriormente propôs-se ao diretor e aos profissionais de educação da referida escola, um treinamento a fim de mostrar a funcionalidade do software educativo Participar 2, que é uma ferramenta desenvolvida exclusivamente para alunos com deficiência intelectual. Os resultados evidenciaram que a escola necessita investir mais em recursos tecnológicos e capacitar os educadores para o uso destes recursos. Percebeuse ainda, que, o software Participar 2, é um tipo de ferramenta que atende às expectativas e necessidades dos alunos com deficiência. Portanto acredita-se que o mesmo pode ajudar a melhorar o desenvolvimento psicomotor, servindo como uma ferramenta de auxílio ao professor-educador.
\end{abstract}

Palavras-Chave: Deficiência Intelectual, Educação Inclusiva, Recursos Tecnológicos.

\footnotetext{
${ }^{1}$ Licenciatura em Ciências Biológicas, Instituto Federal do Piauí, kamenecosta@gmail.com

${ }^{2}$ Licenciatura em Ciências Biológicas, Instituto Federal do Piaú́, wandersonlopes_21@gmail.com

${ }^{3}$ Licenciatura em Ciências Biológicas, Instituto Federal do Piaú́, mauriciosanges11 @ hotmail.com

${ }^{4}$ Me. em Educação com ênfase em Aprendizagem e Formação de Professores - UFPI, Professora efetiva do Instituto Federal do Piauí, afragas3@ifipi.edu.br

${ }^{5}$ Doutora em Humanidades e Artes com ênfase em Ciências da Educação - UNR - Rosário/Argentina, Professora efetiva do Instituto Federal do Piauí, sceci-sousa@hotmail.com
} 


\section{Introdução}

Nesse trabalho, desenvolveremos um debate introdutório sobre a inclusão de alunos com deficiência intelectual com base em pesquisa realizada na Escola Municipal José Francisco Dutra, localizada na cidade de Floriano/PI. Partimos do pressuposto de que a educação é um caminho de transformação, sendo esta um meio capaz de promover mudanças na vida das pessoas.

A inclusão escolar e social deve ocorrer de forma espontânea e contínua, uma vez que é direito humano e obrigação da sociedade acolher e incluir a todos em seu convívio, respeitando as diferenças individuais. Entretanto, as ações e comportamentos exclusivos ainda são uma realidade verificada em uma parcela considerável da nossa sociedade. É importante ressaltar que apenas o acolhimento destes alunos não é suficiente. $\mathrm{O}$ aluno com necessidades educacionais especiais deve ter garantidas as condições efetivas de aprendizagem e desenvolvimento de suas potencialidades.

Ao explorar o tema "Deficiência Intelectual no âmbito escolar: a utilização de recursos tecnológicos na prática pedagógica de professores em Floriano/PI" reforça-se a necessidade de se trabalhar a inclusão efetiva nas salas de aulas e nas universidades, para que se tente minimizar o preconceito e a exclusão. Chama-se ainda a atenção para a importância da utilização das ferramentas digitais como meios facilitadores desse processo, embora constate-se, também, a carência de recursos tecnológicos disponíveis nas escolas.

Tomando como base essas afirmações preliminares, espera-se que tal pesquisa contribua para a sensibilização do poder público e dos profissionais da educação, para que o ato de inclusão efetivamente aconteça, visto que o presente estudo surgiu de uma grande inquietação à respeito das condições de capacitação que os profissionais em educação dispõem para o efetivo trabalho com pessoas com necessidades especiais, bem como os métodos disponibilizados pela escola e a prática pedagógica adotada por professores e demais profissionais que trabalham com alunos deficientes intelectuais e/ou que apresentam outras deficiências.

Neste sentido, a presente pesquisa buscou conhecer as dificuldades encontradas no processo ensino aprendizagem na inclusão de alunos com deficiência intelectual em sala de aula, estas, mencionadas pela gestão escolar, e a partir daí, apresentar recursos tecnológicos que auxiliem na qualidade da aprendizagem dos alunos com essa deficiência, e, como objetivos específicos, identificar se os professores foram capacitados para desenvolver um trabalho com alunos com deficiência intelectual; caracterizar as práticas pedagógicas adotadas pela escola 
junto aos alunos com deficiência intelectual; e discutir metodologias que possam facilitar a inclusão em sala de aula.

\section{Fundamentação Teórica}

A busca incansável do mundo inteiro por educação inclusiva é uma ação política, cultural, social e pedagógica, que busca defender e pôr em prática o direito de todos os alunos de estarem juntos, tantos os ditos normais quanto os que necessitam de atendimentos especiais, aprendendo e participando, sem sofrerem nenhum tipo de discriminação. A educação inclusiva constitui um modelo educacional que segue a concepção de direitos humanos, que busca e apoia a igualdade e diferença como valores e sociedade, que avança buscando acabar com a descriminação que ainda hoje existe fora e dentro do ambiente escolar (BRASIL, 2007).

A Convenção de 2009, além de outras, estabelece a definição de deficiência, a qual segue abaixo, para uma melhor compreensão do tema:

Pessoas com deficiência são aquelas que têm impedimentos de longo prazo de natureza física, mental, intelectual ou sensorial, os quais, em interação com diversas barreiras, podem obstruir sua participação plena e efetiva na sociedade em igualdades de condições com as demais pessoas. (ONU Art. 1 pág. 8)

A deficiência intelectual é causada por inúmeros fatores, dentre eles ambientais, genéticos e congênitos. Como fatores ambientais pode-se citar infecções adquiridas no meio ambiente por cistos de protozoários que atravessam a corrente sanguínea podendo chegar ao cérebro e causar danos irreversíveis, como a hidrocefalia. Dentre os fatores genéticos podemos mencionar os casamentos consanguíneos que resultam em deficiências, como a intelectual. E os fatores congênitos que são aqueles transmitidos de mãe pra filho durante a gravidez, como o vírus da sífilis que se não tratada pode resultar em distúrbios mentais (HONORA E FRIZANCO, 2008).

O primeiro empasse que se encontra para relatar sobre a deficiência intelectual (D.I.) é a maneira correta de como classificá-la. A D.I já foi tida com várias outras nomeações como retardo mental, excepcional, retardado, deficiente, entre outros. Hoje, após modificações de documentos, o termo correto é "pessoa com deficiência", para qualquer tipo de deficiência e no caso de deficiência cognitiva o termo é "pessoa com deficiência intelectual". A deficiência intelectual é uma das deficiências mais encontrada em crianças e adolescentes, caracterizada pela redução no desenvolvimento cognitivo, ou seja, no QI, normalmente abaixo do esperado para a idade da criança ou adulto, acarretando muitas vezes um desenvolvimento mais lento na fala, no desenvolvimento neuropsicomotor e em outras habilidades (VASCONCELOS, 2004). 
A deficiência Intelectual constitui um impasse para o ensino na escola comum e para a definição do seu atendimento especializado, porque ela é complexa em relação ao seu conceito e também possui uma variedade de abordagens e problemas, sendo assim existem grandes dificuldades ao se buscar pelo conceito de deficiência intelectual (BATISTA, 2006).

Para Yayer e Rocin (1989, p. 28), “o termo deficiência é caracterizado pela desvantagem que um indivíduo deve suportar". A deficiência intelectual divide-se em dois grandes grupos: severa e leve. Algumas características de pessoas com deficiência intelectual são: rigidez comportamental (persiste muito tempo em uma determinada tarefa); repetição e rotina (sentemse inseguros e ansiosos diante de situações novas); grande dependência afetiva e comportamental com relação outras pessoas; manifestam apego de modos variados, geralmente em formas infantis que as correspondem à sua idade cronológica; dificuldade para desenvolver comportamentos autorreferidos, relativos a si mesmo como: auto observar-se; e instabilidade emocional (FIERRO, 2004).

Ainda segundo Fierro (2004), a psicometria mais conhecida com QI (quociente intelectual) resulta da divisão da idade cronológica multiplicada por 100. A classificação psicométrica é adotada e mantida primeiro pela Organização Mundial da Saúde (OMS) depois pelo DSM-IV (manual Diagnóstico e estatístico de transtornos mentais), da associação Norte Americana, que classifica deficientes intelectuais os indivíduos com o QI abaixo de 70.

Não é nada simples para um professor de ensino regular com inúmeros alunos, conseguir atender um aluno com deficiência intelectual, a falta de estrutura, a falta de apoio, o despreparo, a má formação e o próprio preconceito, podem contribuir para que as dificuldades aconteçam. É essencial que a escola encontre meios adequados de atuação pedagógica para levar ao alcance dos alunos com deficiência, os conhecimentos disponíveis (FERREIRA, 1993).

Os elementos usados como práticas pedagógicas sejam na sala de ensino regular ou no ensino especial num contra turno, para os alunos com deficiência intelectual, não caminham de modo independente. Estão ligados a fatores externos relacionados a todo quadro escolar. A maneira como os docentes trabalham estes elementos para o ensino e aprendizagem podem desencadear o desenvolvimento ou estagnação na aprendizagem dos alunos. Mas não somente os professores são responsáveis pela prática da inclusão na escola, precisa-se que todos possam agir em parceria com os profissionais da educação, a família e a comunidade como um todo (SILVA, 2011).

Desta forma, a utilização de recursos tecnológicos tem sido objeto de grande valia, sendo estes um facilitador para que essa mudança aconteça. De acordo com Kenski (2007), as tecnologias quando disseminadas e utilizadas corretamente podem influir no desempenho 
profissional, podendo influenciar também, na maneira de como aas pessoas vivem, trabalham e se comunicam. Corroborando com este pensamento VIANA (2004), afirma que:

A era da informação é fruto do avanço das novas tecnologias que estocam, de forma prática, o conhecimento e gigantescos volumes de informações. (...) Estas novas tecnologias permitem-nos acessar não apenas conhecimentos transmitidos por palavras, mas também por imagens, sons, vídeos, dentre outros (p. 11 - 12).

Os recursos tecnológicos são utilizados para facilitar a integração e a inclusão do deficiente intelectual perante a sociedade, estes vão de jogos didáticos até mesmo softwares de computadores, que facilitam e garantem a acessibilidade do deficiente durante o processo pedagógico (GALVÃO FILHO, 2009).

O professor representa um dos mediadores do processo de ensino-aprendizagem, um mediador com intenções. Assim, toda a sua ação antes e durante as aulas precisa ser bem planejada e orientada para que usem de artifícios que despertem na criança não apenas o estímulo pelo novo, mas que adéque a vontade dessa criança de participar deste novo, não apenas conhecendo, mas fazendo parte e interagindo (SILVA, 2011).

De acordo com o Ministério da Educação e Cultura (2010):

\begin{abstract}
A escola comum se torna inclusiva quando reconhece as diferenças dos alunos diante do processo educativo e busca a participação e o progresso de todos, adotando novas práticas pedagógicas. (pág. 9)
\end{abstract}

Também seria de grande valia, divulgar melhor os princípios da inclusão, ou seja, tentando fazer com que a sociedade volte os olhos para sua importância, destituindo preconceitos, estereótipos e estigmas. Dessa maneira, os meios de comunicação poderiam contribuir para que a opinião pública passasse a refletir e a enxergar o deficiente como "PESSOA" não como doente, que precise ser isolado do convívio social. Se a sociedade compreendesse a inclusão não só como um direito, mas uma necessidade aos deficientes, não haveria desigualdades.

\title{
Metodologia
}

A presente pesquisa é de caráter qualitativo com enfoque descritivo. Segundo Lakatos e Marconi (2010) este tipo de abordagem proporciona uma melhor interpretação na obtenção dos resultados da pesquisa. Como instrumento de coleta de dados utilizou-se de uma entrevista por pautas. De acordo com Gil (2011) este tipo de entrevista exibe certo grau de estruturação, uma vez que se direcionar em pontos de relevância que o entrevistador aponta e vai analisando por toda a extensão da entrevista. Obteve-se uma análise interpretativa a partir dos trechos transcritos com a respectiva fala do diretor da escola, uma vez que os professores da instituição 
não puderam participar da entrevista, os quais foram discutidos entrecruzando-os com a fundamentação teórica pertinente. A partir dessa análise a pesquisa adotou uma característica de intervenção na realidade.

O campo de pesquisa e procedimentos de intervenção, deu-se nas instalações da Escola Municipal José Francisco Dutra. Dias após a entrevista com a direção da escola, realizou-se um breve treinamento com alguns profissionais de educação da referida escola, a fim de apresentar a funcionalidade do software educativo Participar 2, esta ferramenta foi desenvolvida exclusivamente para alunos com deficiência intelectual. Esse instrumento de ensino foi criado para colaborar no desempenho de crianças, jovens e adultos com deficiência intelectual em fase de alfabetização, é utilizada por professores nas séries iniciais e avançadas para aprimorar a alfabetização de alunos com este tipo de deficiência. O programa apresenta as letras do alfabeto, o som de cada uma delas e exemplos de objetos em que são utilizadas.

Figura 01 - Representação do software por imagem

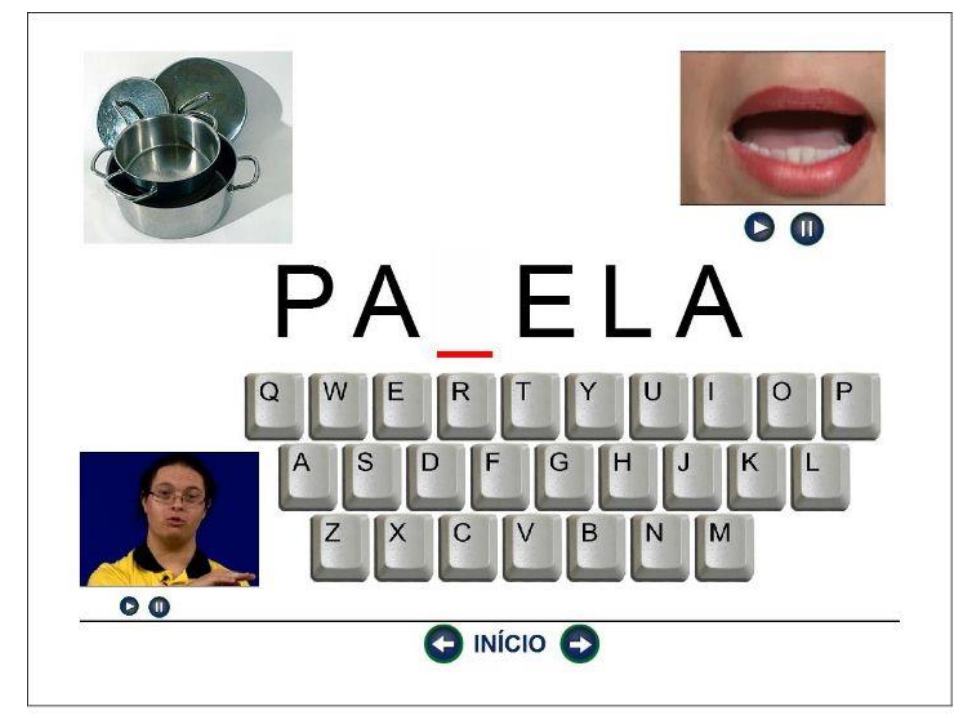

Fonte: Projeto Participar (2015).

\section{Resultados e Discussão}

Inicialmente, a partir das respostas obtidas com os questionamentos narrados na entrevista procurou-se conhecer público da escola, o dia a dia dos professores e alunos a fim de conhecer o público que compõe o tecido macro da pesquisa. Quando se perguntou ao diretor se os professores sentiam dificuldades em trabalhar com o público de deficientes intelectuais e como era o dia a dia destes alunos obtiveram-se as seguintes falas:

“Como a inclusão é um processo que vem sendo trabalhado na nossa escola a mais 10 anos, mesmo assim ainda sentimos dificuldades, pois a cada dia surgem novos casos, novas necessidades, cada aluno tem uma sua realidade e cada um é um caso específico. 
Por isso temos que nos adaptarmos o mais rápido possível para que possamos incluir esse aluno em sala de aula."

"Bom, o dia a dia é de interação, é de descobertas, porque a princípio nos apegamos aos alunos, então como professores temos a capacidade de manipular as situações, e procurarmos integrar todos, mas não deixamos de ter uma atenção maior e especial para essas crianças. Temos também o auxílio do cuidador que também se aproxima muito e auxilia muito o trabalho do professor, temos 10 cuidadores de acordo com a necessidade do aluno tem um preparo com o cuidador que auxilia também o trabalho do professor".

Ao decorrer da fala do diretor observou-se que os professores e toda a comunidade escolar empenham-se em manter a interação de todos no processo de aprendizagem, colaborando para a efetiva participação do sujeito deficiente, como já apontado por Silva (2011). Ao se falar a respeito de capacitação, a fim de se trabalhar com os deficientes intelectuais e se a Secretária Municipal de Educação (SEMED) promovia melhorias para a inclusão destes, obtiveram-se as seguintes respostas:

\footnotetext{
"Sim, nossa escola, cada professor procura se qualificar se capacitar e estudar, porque é a realidade do dia a dia, da sala de aula, para procurar conhecer a necessidade. Também temos o apoio da própria escola e temos professores capacitados para isso. Tem a sala multifuncional. Ainda também a sala do atendimento especial, e dois professores nas respectivas salas que nos auxiliam nas necessidades de cada um."

"A SEMED juntamente com a parte de apoio da inclusão da Coordenação de Educação inclusiva, toda semana oferece um dia " $D$ " de encontro. Toda quinta feira é o dia de encontro dos professores onde se discutem e fazem estudos de caso. Onde cada caso é trabalhado de acordo com a necessidade dos alunos, e o que é acontece no dia a dia de sala de aula, e dependendo da situação e do tema mais discutido é que acontecem as formações de capacitações que a própria SEMED nos contempla, e também as situações de estudo de apoio maior, de acordo com as necessidades da escola."
}

Percebe-se que há um interesse particular na busca de capacitação por parte do corpo docente da escola em questão, assim como há uma preocupação maior para garantir a inclusão no âmbito educacional.

E por fim, foram questionados quais os tipos de deficiências é possível atender na escola e quais eles atendem:

\footnotetext{
"Na nossa escola nós temos um número muito grande de autistas, mais também nós temos cadeirantes, alunos com deficiência visual, alunos com deficiência auditiva, temos alunos com deficiência intelectual, temos também alunos com Transtorno do Déficit de Atenção com Hiperatividade (TDAH). Então, são situações que, como a inclusão é para envolver todos os tipos de alunos, não importa a necessidade, nós temos que procurar recebê-los e se adaptar da melhor maneira possível o mais rápido ainda."
}

Ao longo da pesquisa identificou-se que a escola conta na sua totalidade com 429 (quatro centos e vinte e nove) alunos, dentre eles 21(vinte e um) alunos com as mais diversas deficiências, 10 (dez) autistas, 3 (três) surdos, 3 (três) cegos, 2(dois) deficientes físicos e 3 (três) deficientes intelectuais. A escola também conta com a ajuda de 10 (dez) cuidadores, auxiliando o trabalho do professor. Ao final da entrevista realizou-se um pequeno treinamento com três 
funcionários da escola (um diretor, um coordenador, um professor), com o propósito de apresentar o benefício da inserção de recursos tecnológicos nas práticas pedagógicas e no dia a dia da sala de aula. Ao fim do treinamento, conseguiu-se constatar que o software educativo Participar 2 seria bem aceito na instituição, porém o único empecilho é a falta de máquinas para instalação do recurso, e segundo a fala do público treinado garantiria auxilio para o professor durante a alfabetização de pessoas com deficiência intelectual, fazendo menção ao pensamento de Kenski (2007), como citado acima.

\section{Conclusões}

Entende-se que a deficiência intelectual é ocasionada das mais diversas formas possíveis. Nesse sentido, esse trabalho surge como um mecanismo para proporcionar aos professores e à sociedade geral maior conhecimento e informação sobre a D.I. Considerando os resultados desta pesquisa, percebemos a dificuldade de caracterização do sujeito com deficiência. Outro ponto importante a ser observado é que muitas escolas ainda sofrem com a carência de recursos tecnológicos que por sua vez seriam facilitadores no processo de alfabetização e inclusão. Certamente há uma busca do conhecimento por parte de toda equipe docente para se trabalhar com os deficientes.

Contudo, conclui-se que, a discussão apresentada ao longo desse trabalho aponta como proposta alternativa realizar treinamentos e cursos de formação para capacitar a equipe pedagógica das escolas que recebem alunos com necessidades especiais. Espera-se que essa pesquisa possa também contribuir de maneira satisfatória para o diálogo entre as formas de pensar e agir sobre o processo ensino aprendizagem das pessoas com deficiência intelectual na sociedade contemporânea.

\section{Referências}

BATISTA, C. A. M.; MANTOAN, M. T. E. In GOMES, Adriana L. Limaverde ett all. . Atendimento Educacional Especializado: deficiência mental. SEESP/ SEED/ MEC Brasília/DF, 2007.

BRASIL. Ministério da Educação. Secretaria de Educação Especial. Política Nacional de Educação Especial na Perspectiva da Educação Inclusiva. Brasília: MEC Batista, Cristina Abranches Mota. Educação inclusiva : atendimento educacional especializado para a deficiência mental. 2. ed. Cristina Abranches Mota Batista, Maria Teresa Egler /SEESP, 2007

BRASIL. Educação Inclusiva. Atendimento Educacional Especializado. Deficiência Mental. São Paulo: MEC/SEESP, 2007. 
FERREIRA, Isabel Neves. Caminhos do aprender: Uma alternativa educacional para criança portadora de deficiência mental. Brasília: coordenação nacional para integração da pessoa com deficiência, 1993.

FIERRO, A. A deficiência mental. In: COLL, César; et al. Desenvolvimento Psicológico e educação: trad. Fátima Murad. Porto Alegre, 2004 ed. Artmed.

GALVÃO FILHO, T. A. A Tecnologia Assistiva: de que se trata? In: MACHADO, G. J. C.; SOBRAL, M. N. (Orgs.). Conexões: educação, comunicação, inclusão e interculturalidade. 1 ed. Porto Alegre: Redes Editora, 2009b, p. 207-235.

HONORA M.; FRIZANCO M. L. Esclarecendo as deficiências: Aspectos teóricos e práticos para contribuir com uma sociedade inclusiva. Ciranda Cultural, 2008.

GIL, Antônio Carlos. Métodos e técnicas de pesquisa social. São Paulo: Atlas, 2011.

KENSKI, V. M. Educação e tecnologias: O novo ritmo da informação. Campinas: Papirus, 2007.

LAKATOS, E. M.; MARCONI, M. A. Fundamentos de metodologia científica. 7. ed. São Paulo: Atlas, 2010.

ORGANIZAÇÃO DAS NAÇÕES UNIDAS - ONU. Convenção sobre os Direitos das Pessoas com Deficiência. Nova Yorque, 2006.

SEESP/ SEED/ MEC, A Educação Especial na Perspectiva da Inclusão Escolar: A Escola Comum Inclusiva, Fascículo I, Brasília, 2010.

SILVA, F. G. Inclusão escolar de alunos com deficiência intelectual: o Atendimento Educacional Especializado (AEE) em discussão. Universidade Estadual Do Ceará Centro De Educação Mestrado Acadêmico Em Educação. Fortaleza - Ceara, 2011.

UNB, Universidade de Brasília. Projeto Participar. Brasília: [s.n.], 2015. Disponível em: <http://www.projetoparticipar.unb.br/participar2>. Acesso em: 25 jun. 2017.

VASCONCELOS, M. M. Retardo mental. Jornal de pediatria. Porto Alegre, v. 80, n.2, p. S71-S82. Abr. 2004.

VIANA, M. A. P. Internet na Educação: Novas formas de aprender, necessidades e competências no fazer pedagógico. In: MERCADO, L. P. L. (Org.) Tendências na utilização das tecnologias da informação e comunicação na educação Maceió: EDUFAL, 2004. 228p.

YAYER, P.; RONCIN, C. A integração da criança deficiente na classe. Trad. Maria Ermandina Galvão; Gomes Pereira Lisboa. Editora manole, 1989. 